\title{
The effect of Seizure on School Attendance among Children with Epilepsy: A follow-up study at the Pediatrics Neurology Clinic, Tikur Anbessa Specialized Hospital, Addis Ababa, Ethiopia
}

Oumer Hassen ( $\nabla$ oumerhh@gmail.com )

Haramaya University College of Health and Medical Sciences https://orcid.org/0000-0003-3560-5117

\section{Ayalew moges Beyene}

Addis Ababa University School of Medicine

\section{Research article}

Keywords: Epilepsy, Epileptic attack, School absenteeism, Childhood epilepsy, Epilepsy in Ethiopia

Posted Date: February 11th, 2020

DOI: https://doi.org/10.21203/rs.2.11162/v3

License: (c) (1) This work is licensed under a Creative Commons Attribution 4.0 International License.

Read Full License

Version of Record: A version of this preprint was published at BMC Pediatrics on June 3rd, 2020. See the published version at https://doi.org/10.1186/s12887-020-02149-y. 


\section{Abstract}

Backgound: Epilepsy is the most common chronic neurological disease seen in Pediatrics Neurology Units in developing countries negatively affecting school attendance and academic performance. Comorbid learning and behavioral problems may also contribute to the academic difficulties among children with epilepsy. The main aim of this study is to assess the extent and factors contributing school absenteeism among school-aged children and adolescents with epilepsy.

Methods: A hospital based follow-up study was conducted among school-aged children and adolescents with epilepsy between the ages of 7-18 years attending an outpatient Pediatric Neurology Clinic. A sample of 183 children and adolescents were included in the study. The participants (children and their parents/caregivers) gave information concerning the socio-demographic characteristics of the child and the primary caregiver, information regarding the child's presentation and whether or not they disclosed to teachers and peer. Medical charts were thoroughly reviewed on the diagnosis and prognosis. Study participants characteristics were described and logistic regression was used to determine factors associating with school absenteeism.

Results: School absenteeism ( $\geq 1$ days/month) over six month period among children aged 7-18 years with epilepsy was $69.4 \%$. Factors which correlated with school absenteeism included female sex (AOR $2.19,95 \% \mathrm{Cl} 1.03-4.84$ ), children with known causes for seizures AOR 2.51, 95\% Cl 1.09-5.86), having seizure at school and longer epilepsy duration.

Conclusion recommendation: School absenteeism was found in over two thirds of children aged 7-18 years with epilepsy attending an outpatient epilepsy clinic in Ethiopia.

\section{Background}

Epilepsy is a disorder of the brain characterized by an enduring predisposition to generate seizures and by the neurobiological, cognitive, psychological, and social consequences of this condition and clinical diagnosis of epilepsy usually requires the occurrence of at least 1 unprovoked epileptic seizure with either a second such seizure or enough EEG and clinical information to convincingly demonstrate an enduring predisposition to develop recurrences. For epidemiologic and commonly for clinical purposes, epilepsy is considered to be present when 2 or more unprovoked seizures occur in a time frame of longer than $24 \mathrm{hr}$.

Epilepsy is the most common chronic neurological disease seen in Pediatrics Neurology Units in developing countries(2) and has prevalence of 5-10/1000 in developing countries.(3) A prior study from our center, in 2013 reported that seizure disorders were found in $45.6 \%$ of all children attending our outpatient neurology clinic. Of these, $28.8 \%$ of seizure disorders (30 of 104) were of unknown cause and $71.2 \%$ (74 of 104) were secondary to other disorders.(4) 
Children with epilepsy are prone to educational underachievement as a result of co-morbid learning and behavioral problems. Other factors that may contribute to poor school performance amongst epilepsy patients may include overprotective parental attitudes, a lack of academic motivation, and low selfesteem. The impact of epilepsy on school attendance may also contribute to the academic difficulties of children with epilepsy.

Although most studies addressing academic performance in school-aged children with epilepsy are focused on academic achievement and quality of life of children with epilepsy, only a few address the impact of epilepsy on school attendance. One prospective study from a specialty pediatric epilepsy clinic in Brazil found that $88 \%$ of patients in the study missed at least one day of school due to seizures. Nearly half of parents (46\%) believed that if the child had a seizure at school he/she should leave school immediately.(5)

According to Fernandes (2005), several variables may be related to the school absenteeism, such epilepsy type, severity, age at onset, but also the beliefs of parents, teachers and school friends, who often stigmatize children with epilepsy, believing that such children present more behavioral problems than healthy children of similar intellect.(6)

In Ethiopia, a recent survey of knowledge, attitude, and practice of teachers towards people with epilepsy (PWE) found that ninety percent knew epilepsy as a disease, $51.3 \%$ indicated that the source of information was acquaintances with PWE and $28.6 \%$ had a student with epilepsy in class. Although 89.2 $\%$ of the teachers would allow PWE into their class, the majority (76.7\%) preferred that the epilepsy be cured or controlled before attendance because they were perceived insane more than infectious explaining(7).

Our study aimed to assess the effect of childhood epilepsy on school attendance and determine e reasons for absenteeism.

\section{Methods And Materials}

\section{Study Setting}

The study was conducted in the outpatient pediatric neurology clinic in Addis Ababa, Ethiopia at Tikur Anbessa Specialized Hospital (TASH). This hospital is the only pediatric Teaching Hospital of the Addis Ababa University, College of Health Sciences, and School of Medicine, located in Lideta sub-city, Addis Ababa. It is the largest referral hospital in Ethiopia with a number of specialties and subspecialty units. The hospital has totally around 600 admission beds and serves about 250,000 outpatients annually.

The pediatric neurology clinic is held five half-days per week, and is staffed by trained nurses, a general practitioner, Pediatric and Child Health Residents, and supervised by the pediatric neurologists. All children in Addis Ababa or surrounding regions with neurological concerns are either seen at this clinic, or in a private clinic, staffed by the same pediatric neurologists. The TASH pediatric neurology clinic sees 
approximately 600 children and adolescents from 0-18 years per month. Clinically stable patients with epilepsy who have with good seizure control are appointed to come every 2-3 months.

\section{Design and Study Population}

This cross-sectional study was conducted at the PNC in TASH between April and July 2018 . We invited all school age children and adolescents aged 7-18 years, attending the clinic with their primary caretaker during the study period, and who had a six month or longer history of epilepsy to participate. Children with physical disability who were unable walk independently, and those in whom parental consent was not obtained were excluded.

Consented study participants were included in the study until the sample size was attained.

\section{Data collection}

A structured study questionnaire was administered to families by 4 pediatric residents, under the supervision of the attending neurologist.

We defined school absenteeism as the percentage of missed school days from January 1, 2018 until the date of completion of the questionnaire. Data analysis was done using the Statistical Package for Social Sciences (SPSS) version 22. School absenteeism was reported as a mean percentage and interquartile range. Variables potentially associated with absenteeism were assessed by binary logistic regression analysis. Variables which showed significant association with school attendance in binary logistic analysis were included at once in logistic regression analysis to calculated adjusted odds ratios with the $95 \%$ confidence interval. For all statistical analysis a $p$ value of $<0.05$ is considered statistically significant.

Symptomatic seizure: defined as seizure/epilepsy that follows an injury (head injury, CNS infection, stroke, brain tumor, and surgery) to the brain known to be capable of causing epilepsy.(1)

Seizure control was defined as complete if children were seizure-free $x>6$ months, as partial if there was a $>50 \%$ reduction in seizure and as poor if they had one or more seizure per month over of the last 6 months despite trials of at least two different AEDs at optimum doses alone or in combination with adequate compliance.(8)

\section{Results}

\section{Socio-demographic characteristics}

This study included 183 children with epilepsy and demographics are shown in Table 1. More than half $(55.7 \%)$ were male and most $(72.7 \%)$ were in the age group of 7 to 12 years.

Two hundred twenty-three (67.2\%) attended primary school. Fifty six (30.6\%) were attending nursery school which is not age appropriate, and 84 (45.9\%) repeated at least one grade. 
Data regarding caregivers is shown in Table 2 . The primary caregiver for the child was reported to be mothers in $71(38.8 \%)$, fathers in $34(18.6 \%)$ and both parents equally in $68(37.2 \%)$ of cases. The majority of the primary caregivers were married (80.9\%).

One hundred eight (59.9\%) primary caregivers completed secondary school education or greater. Only 140 (76.5\%) of the care givers disclosed their income, among whom only $75(53.6 \%)$ earned $>1500$ Birr/month.

\section{Seizure characteristics}

Table 3 lists seizure characteristics for the study population. The mean age at onset was 4.6 years and mean duration of epilepsy was 5.7 years. One hundred and thirty two $(72.1 \%)$ had generalized epilepsy, $49(26.8 \%)$ had focal epilepsy and the remaining $2(1.1 \%)$ had unclassified epilepsy.

Most patients $104(56.8 \%)$ had seizures once per month or less. One hundred and thirty $(71.4 \%)$ received mono-therapy. Of the total 183 study subjects About 44(24.0\%) had a known cause for epilepsy; while the rest $139(76.0 \%)$ do not have a known cause. When we see level of seizure control; complete control was observed in 92(50.3\%), partial control in 57(31.1\%), poor control in 33(18.1\%) and not documented in one patients (Table 3 ).

School Absenteeism:

One hundred and twenty seven (69.4\%) children were reported to miss school days due to seizures and most (90) missed between 1 to 10 days, among children who missed school days $25.9 \%$ of children missed more than $50 \%$ of school days (Table 4 \&Figure 1 ) and only $2.2 \%$ were pulled out of school during that year (2018). Reasons given by caregivers for missed school included medical appointments ((80.3\%), seizure occurring prior to school day $(50.4 \%)$, and seizure occurring at school (21.3\%) (Figure 2 ). Additionally, the primary care givers allowed $19.2 \%$ of their children to miss school days even when there is no illness, predominantly due to concern that the child may have a seizure in school in $75 \%$ of cases.

Caregivers reported that teachers had expressed apprehension to them about their child's epilepsy in $71(38.2 \%)$ of the cases. The teachers were mainly concerned because they fear that other students could be disturbed and the school performance of affected children may decline. In $17 \%$ of cases, teachers requested that children with epilepsy should stay at home. Predictors for school absenteeism are shown in Table 5. Older age group, female sex, epilepsy duration $\geq 5$ years, repeating one or more grades, prior seizure at school, higher seizure frequency, longer seizure duration and disclosing seizure to teachers, were associated with school absenteeism. Further analysis by multivariable analysis showed female students (AOR 2.19: 1.03, 4.84), having a known cause for epilepsy (AOR 2.51: 1.09, 5.86), and having longer duration of seizure (seizure experience for more than five years) (AOR 2.36: 1.09, 5.15) were identified as independent determinants of poor school attendance.

\section{Discussion}


In an endeavor to assess the effect of seizure on school absenteeism in school age children and adolescents between the ages of 7 and 18 years who were attending follow up at the PNC in Tikur Anbessa Specialized Hospital (TASH), 183 children with epilepsy were recruited. To our knowledge this study is the first of its kind in Ethiopia which is set to determine the extent of epilepsy among school aged children and to identify factors affecting school attendance among children with epilepsy. In order to design future interventions to improve school attendance, identifying the factors affecting school absenteeism in children with epilepsy is very important

In this study, school absenteeism among children aged 7-18 years at PNC follow up were $69.4 \%$. Poor attendance is less in this study compared to the research in Brazil (88\%) but higher than the study in Sera lion $(50 \%)$ and a study by $\operatorname{CDC}(36 \%)(5,9,10)$. The differences in estimates poor school attendance could be attributed to the difference in sample size, the demographic characteristics, seizure duration, and the varying definition of poor attendance.

More children with epilepsy within the age group of 13-18 years (82\%) missed school. The higher proportion of absenteeism in this age group may reflect the difficulty of coping with epilepsy among older children due to possible longer duration of the disease since onset and fear of dealing with the stigma associated with the illness.

Similar to the other studies, this study finding show that the major reason for missed school days was due to seizure $(20,22)$. Totally four children $(3.2 \%)$ ceased attending school in our study is fewer than reported in a study done in Serra lion which was about $20 \%$. Education is very important for all children and especially for children with epilepsy as it could facilitate adaptive functionality and better integration in the society. Therefore, cessation of education should not an option in children with epilepsy rather allowing children to come to clinic after school after medical appointments and improved seizure control might help children decrease absenteeism.

The proportion of the two sexes in this study was similar to the proportion reported in a study that determined the incidence of epilepsy in rural central Ethiopia(11).In this study, there were statistically significant association between female sex and missed school days. More female (79\%) than male (63\%) children with epilepsy missed school days. Female children with epilepsy were 2.2 times more likely to miss school days than their male counterparts. In developing countries like Ethiopia where enrollment and retention of female children at school is poor, this result is expected. In addition, female children with epilepsy are at increased risk of developing depression due to the illness which could perhaps affect school attendance negatively. Our finding, however, contradicts the finding of a study that showed higher proportion of school attendance among female than male children(12). The finding of this study shows the need to reach out for female children with epilepsy even more than the male children. Stronger social support to boost the confidence and better function of children with epilepsy are required.

More number of care givers has disclosed the condition of the children to the teachers (86.9\%). As teachers could support children with epilepsy, it is encouraging to know that most of the careers willingly disclose the status of the children to their teachers. Unfortunately, more number of the children whose 
status is known by the teachers missed school day as opposed to children whose status was not disclosed to their teacher. The preference of the teachers to let the children stay at home till their seizure is cured before coming to school can be the reason for poor attendance(7). Therefore, it is important to equip teachers with the knowledge and resources required to handle children with epilepsy to avoid more number of missing days. Furthermore, teachers and care takers could plan ways to make up for missed days of school to improve attendance of the children.

Having symptomatic seizure and longer duration of seizure identified as the independent determinants of missing school. This could be associated with the illness and potential fear of stigma associated with having the illness. Children who experienced seizure at school are less likely to miss school than those who never had seizure at school. This could perhaps be due to a good collaboration of the care takers and teachers in reassuring the children with seizure.

Greater proportions of the primary caregivers of the children were married $(80.9 \%)$ and more than half of had attended high school or higher education (59.6\%) and have a secured monthly income (68.2\%). These characteristics of careers are expected to affect school attendance of children with epilepsy positively. Though, more proportion of children raised by parents of lower education level missed school than those raised by parents of higher education level, our findings fail to demonstrate a statistically significant association between family size, marital status of parents, socioeconomic status and educational status of parent's with school absenteeism.

As shown in our results despite the absence of any illness the parents allowed $19.2 \%$ of their children to miss school days. Excessive fear and concerns of care takers of children with epilepsy need to be tackled through reassurance and education to improve school attendance.

In this study, though not statistically significant, children with more than one seizure per month have missed school more than those who had less frequent seizure but other studies suggest the negative impact of seizure frequency on intellectual performance resulting in low academic performance and difficulty in learning(13). Direct effect of seizure on wellness of the children and its indirect effect on cognition may both result in poor attendance among children with epilepsy (13-16).

More children who repeated grade $(78.6 \%)$ missed more school days than those who never repeated their grade $(61.6 \%)$. There is a statistically significant association between repeating grade and poor attendance. A possible inference from this is that repeating a grade could negatively affect school attendance. Children with epilepsy are likely to have associated learning difficulties, therefore each child learning abilities need to be assessed before commencement and during the learning process. Therefore, the schools need to identify trained personnel who could identify learning challenges of the child and who could suggest potential measures to be taken to improve progress of learning of the children with epilepsy to avoid repeating classes.

\section{Conclusion}


This study identified that school absenteeism is very common among children aged 7-18 years at PNC follow up (69.4\%). It was learnt that experience of seizure has significant effect on children's school attendance. Females, seizure duration for more than five years, symptomatic epilepsy are significantly associated with school absenteeism.

\section{Recommendations}

There is a need for collaborative action by clinicians, teachers, care takers and school administration to improve attendance. Facilitating a regular neuropsychological assessment, continuous follow up and after school clinic will help children in decreasing absenteeism. Training of the teachers and care takers on how to deal on apprehension is necessary. The importance attendance and performance at school for better integration of the children in the society should be emphasized. Special support group should be established in schools to cater the needs and limitations of children with epilepsy.

\section{Abbreviations}

$\begin{array}{ll}\text { ADHD } & \text { Attention Deficit Hyperactivity Disorder } \\ \text { AOR } & \text { Adjusted Odds Ratio } \\ \mathrm{CI} & \text { Confidence Interval } \\ \text { CWE } & \text { Children with Epilepsy } \\ \text { CNS } & \text { Central Nervous System } \\ \text { CSHCN } & \text { Children with Special Health Care Needs } \\ \text { EEG } & \text { Electroencephalography } \\ \text { FMoH } & \text { Federal Ministry of Health } \\ \text { ILAE } & \text { International League against Epilepsy } \\ \text { OR } & \text { Odds Ratio } \\ \text { MDG } & \text { Millennium Development Goals } \\ \text { NCDs } & \text { Non-Communicable Diseases } \\ \text { PNC } & \text { Pediatric Neurology Clinic } \\ \text { SPSS } & \text { Statistical Package for Social Sciences } \\ \text { TASH } & \text { TikurAnbessa Specialized Hospital } \\ \text { WHO } & \text { World Health Organization } \\ \text { SSNPR } & \text { Southern Nations, Nationalities, and Peoples' Region }\end{array}$

\section{Declarations}


Ethical approval and consent to participate: Ethical clearance was obtained from the Department of Pediatrics and Child Health Research and Publications Committee of the School of Medicine, College of Health Sciences, Addis Ababa University and it was a written consent.

Consent for publication: Not required

Availability of data and material: The data sets generated or analyzed during the current study are not publicly available due to intuitional policy but are available from corresponding author on reasonable request.

Competing interests: The authors declare that they have no competing interests.

Funding: No funding was obtained for this study.

Authors' contributions: $\mathrm{OH}$ was responsible for overall conceptualization, writing most of the article and conduct of the study.AM was a pediatric neurologist who contributed toward modifications and finalizing the article.

\section{Acknowledgements}

I would like to acknowledge the staff members at the pediatric neurology clinic who helped in data collection. This study would have not been materialized without the primary caregivers of the children and adolescents at the PNC who consented to participate. We are also very grateful for the encouragement and support provided by my wife and other close family members.

\section{References}

1. Kliegman RM, Behrman RE, Jenson HB, Stanton BM. Nelson textbook of pediatrics (Edition 20.). Phialdelphia, PA: Elsevier: Elsevier Health Sciences; 2016.

2. Izuora G, Iloeje S. A review of neurological disorders seen at the paediatric neurology clinic of the university of Nigeria teaching hospital, Enugu. Annals of tropical paediatrics. 1989;9(4):185-9.

3. Scott RA, Lhatoo SD, Sander JW. The treatment of epilepsy in developing countries: where do we go from here? Bulletin of the World Health Organization. 2001;79(4):344-51.

4. Moges A GS, Zenebe G, Kotagal S. Pattern of Neurological Disorder at Pediatric Outpatient Neurologic services at Tikur Anbessa Specialized Hospital. Ethiopian Journal of Pediatric and Child Health. 2017;XIV, No. 2.

5. Aguiar BV, Guerreiro MM, McBrian D, Montenegro MA. Seizure impact on the school attendance in children with epilepsy. Seizure. 2007;16(8):698-702.

6. Fernandes PT, Snape DA, Beran RG, Jacoby A. Epilepsy stigma: what do we know and where next? Epilepsy \& Behavior. 2011;22(1):55-62. 
7. Gebrewold MA, Enquselassie F, Teklehaimanot R, Gugssa SA. Ethiopian teachers: their knowledge, attitude and practice towards epilepsy. BMC neurology. 2016;16(1):167.

8. Holmes GL, Engel J. Predicting medical intractability of epilepsy in children How certain can we be? Neurology. 2001;56(11):1430-1.

9. Pastor PN, Reuben CA, Kobau R, Helmers SL, Lukacs S. Functional difficulties and school limitations of children with epilepsy: findings from the 2009-2010 National Survey of Children with Special Health Care Needs. Disability and health journal. 2015;8(2):231-9.

10. Ali DB, Tomek M, Lisk DR. The effects of epilepsy on child education in Sierra Leone. Epilepsy \& Behavior. 2014;37:236-40.

11. Tekle-Haimanot R, Forsgren L, Ekstedt J. Incidence of epilepsy in rural central Ethiopia. Epilepsia. 1997;38(5):541-6.

12. Duggan M. Epilepsy and its effects on children and families in rural Uganda. African health sciences. 2013;13(3):613-23.

13. Bjørnæs H SK, Henriksen O, Løyning Y. . The effects of refractory epilepsy on intellectual functioning in children and adults. A longitudinal study. Seizure. 2001;10(4):250-9.

14. Aldenkamp AP, Weber B, Overweg-Plandsoen WC, Reijs R, van Mil S. Educational underachievement in children with epilepsy: a model to predict the effects of epilepsy on educational achievement. Journal of Child Neurology. 2005;20(3):175-80.

15. Bulteau C, Jambaque I, Viguier D, Kieffer V, Dellatolas G, Dulac O. Epileptic syndromes, cognitive assessment and school placement: a study of 251 children. Developmental medicine and child neurology. 2000;42(5):319-27.

16. Mitchell WG, Scheier LM, Baker SA. Psychosocial, behavioral, and medical outcomes in children with epilepsy: a developmental risk factor model using longitudinal data. Pediatrics. 1994;94(4):471-7.

\section{Tables}

Table1. Socio demographic characteristics of school age children and adolescents with seizure disorder attending follow up at PNC in TASH between April and July, 2018 


\begin{tabular}{|c|c|c|}
\hline Variables & Frequency & Percentage \\
\hline $\begin{array}{l}\text { Age groups } \\
7-12 \\
13-18 \\
\text { Mean } / \pm \text { SD }=10.47 / 2.9\end{array}$ & $\begin{array}{l}133 \\
50\end{array}$ & $\begin{array}{l}72.7 \\
27.3\end{array}$ \\
\hline $\begin{array}{l}\text { Sex } \\
\text { Male } \\
\text { Female }\end{array}$ & $\begin{array}{l}102 \\
81\end{array}$ & $\begin{array}{l}55.7 \\
44.3\end{array}$ \\
\hline $\begin{array}{l}\text { Birth order } \\
\text { First } \\
\text { Second } \\
\text { Third } \\
\text { Greater than } 3\end{array}$ & $\begin{array}{l}82 \\
42 \\
26 \\
33\end{array}$ & $\begin{array}{l}44.8 \\
23.0 \\
14.3 \\
18\end{array}$ \\
\hline $\begin{array}{l}\text { Family size including parents }(\mathrm{n}=175) \\
<5 \\
\geq 5 \\
\text { Mean } / \pm \mathrm{SD}=4.85 / 1.8\end{array}$ & $\begin{array}{l}81 \\
94\end{array}$ & $\begin{array}{l}46.3 \\
53.7\end{array}$ \\
\hline $\begin{array}{l}\text { Address } \\
\text { Addis Ababa } \\
\text { Out of Addis Ababa }\end{array}$ & $\begin{array}{l}118 \\
65\end{array}$ & $\begin{array}{l}64.5 \\
35.5\end{array}$ \\
\hline $\begin{array}{l}\text { Childs level of education } \\
\text { Nursery } \\
\text { Primary school } \\
\text { Secondary school }\end{array}$ & $\begin{array}{l}56 \\
123 \\
4\end{array}$ & $\begin{array}{l}30.6 \\
67.2 \\
2.2\end{array}$ \\
\hline $\begin{array}{l}\text { Repeated grade } \\
\text { Never repeated } \\
\text { Repeated }\end{array}$ & $\begin{array}{l}99 \\
84\end{array}$ & $\begin{array}{l}54.1 \\
45.9\end{array}$ \\
\hline
\end{tabular}


Table2. Socio demographic characteristics of primary caregivers of school age children and adolescents with seizure disorder attending follow up at PNC in TASH between April and July, 2018

\begin{tabular}{llll}
\hline Variables & & Frequency & Percentage \\
\hline Marital status of primary care giver & Single & 9 & 4.9 \\
& Married & 148 & 80.9 \\
& Divorced & 15 & 8.2 \\
& Widowed & 11 & 6.0 \\
\hline Educational status of primary care & Less than high & 73 & 40.3 \\
giver n=181 & school & 39 & 21.5 \\
& High school & 69 & 38.1 \\
& Collage level and & & \\
& above & & \\
\hline Occupational status of primary care & Government & 41 & 22.9 \\
giver & House wife & 36 & 20.1 \\
& Private work & 68 & 38.0 \\
& Merchant & 13 & 7.3 \\
& Farmer & 9 & 5.0 \\
& Other & 7 & 3.9 \\
\hline Family monthly income $(\mathrm{n}=140)$ & $<1500$ birr & 65 & 46.4 \\
& $>1500$ birr & 75 & 53.6 \\
\hline
\end{tabular}

Table3. Seizure related information of school age children and adolescents with seizure disorder attending follow up at PNC in TASH between April and July, 2018 


\begin{tabular}{|c|c|c|c|}
\hline \multicolumn{2}{|l|}{ Variables } & Frequency & Percentage \\
\hline \multirow{4}{*}{$\begin{array}{l}\text { Age at which seizure was } \\
\text { started }\end{array}$} & $<1$ year & 36 & 19.7 \\
\hline & $1-5$ year & 76 & 41.5 \\
\hline & $>5$ year & 71 & 38.8 \\
\hline & Mean $/ \pm S D=4.6 / 3.6$ & & \\
\hline \multirow[t]{2}{*}{ Duration of epilepsy in years } & $<5$ & 70 & 38.3 \\
\hline & $\begin{array}{l}\geq 5 \\
\text { Mean } /+S D=5.7 / 3.5\end{array}$ & 113 & 61.7 \\
\hline \multirow[t]{3}{*}{ Seizure type } & Focal onset & 49 & 26.8 \\
\hline & Generalized onset & 132 & 72.1 \\
\hline & Unknown onset & 2 & 1.1 \\
\hline \multirow[t]{2}{*}{ Seizure frequency } & $\leq 1$ per month & 104 & 56.8 \\
\hline & $>1$ per month & 79 & 43.2 \\
\hline \multirow[t]{5}{*}{ Type of therapy $(n=182)$} & Monotherapy & 130 & 71.4 \\
\hline & Monotherapy \& have side & 3 & 1.6 \\
\hline & effects & 46 & 25.3 \\
\hline & Poly-therapy & 3 & 1.6 \\
\hline & $\begin{array}{l}\text { Poly-therapy \& have side } \\
\text { effects }\end{array}$ & & \\
\hline \multirow[t]{2}{*}{ Comorbidity } & Yes & 47 & 25.7 \\
\hline & No & 136 & 74.3 \\
\hline \multirow{2}{*}{$\begin{array}{l}\text { Symptomatic epilepsy with a } \\
\text { known cause }\end{array}$} & Yes & 44 & 24.0 \\
\hline & No & 139 & 76.0 \\
\hline \multirow[t]{4}{*}{ Seizure control } & Complete seizure control & 92 & 50.3 \\
\hline & Partial seizure control & 57 & 31.1 \\
\hline & Poor seizure control & 33 & 18.0 \\
\hline & Not documented & 1 & 0.5 \\
\hline
\end{tabular}

Table4. Effect of seizure on school attendance of school age children and adolescents with seizure disorder attending follow up at PNC in TASH between April and July, 2018. 


\begin{tabular}{|c|c|c|c|}
\hline Variables & & Frequency & Percentage \\
\hline Ever miss a school day because & Yes & 127 & 69.4 \\
\hline of seizure & No & 56 & 30.6 \\
\hline Number of days missed $(n=127)$ & $<10$ days & 90 & 70.9 \\
\hline & 10-30 days & 33 & 25.9 \\
\hline & Pulled out of school & 4 & 3.2 \\
\hline & Mean $/ \pm \mathrm{SD}=12.6 / 31$ & & \\
\hline$\%$ of days missed $(n=127)$ & $<50 \%$ & 90 & 70.9 \\
\hline & $\geq 50 \%$ & 37 & 29.1 \\
\hline $\begin{array}{l}\text { Reasons for missing school due } \\
\text { to seizure }(n=127)\end{array}$ & $\begin{array}{l}\text { Had a seizure before } \\
\text { school }\end{array}$ & 64 & 50.4 \\
\hline & Had a seizure at school & 27 & 21.3 \\
\hline & and needed to go home & 102 & 80.3 \\
\hline & Had a medical & 1 & 0.8 \\
\hline & appointment & 1 & 0.8 \\
\hline & Had a test scheduled & & \\
\hline & Other & & \\
\hline Seizure at school & Yes & 88 & 48.1 \\
\hline & No & 95 & 51.9 \\
\hline Go home before the end of & Yes & 81 & 92 \\
\hline $\begin{array}{l}\text { classesafter seizure in } \\
\text { school }(\mathrm{n}=88)\end{array}$ & No & 7 & 8 \\
\hline Should go home from schools & Should go home & 58 & 31.7 \\
\hline immediately for reasons of & immediately & 125 & 68.3 \\
\hline seizure & Can stay at school if well & & \\
\hline Apprehension regarding the & Yes & 71 & 38.2 \\
\hline diagnosis of epilepsy & No & 110 & 60.8 \\
\hline Type of apprehension $(n=69)$ & Fear failing to assist & 14 & 17.7 \\
\hline & Fear reduced school & 27 & 34.2 \\
\hline & activity & 38 & 48.1 \\
\hline & Fear of disturbing others & & \\
\hline Teacher suggested stay at home & Yes & 31 & 17.0 \\
\hline $\begin{array}{l}\text { as the child had seizure } \\
\text { experience }\end{array}$ & No & 151 & 83.0 \\
\hline Allowed child to miss a day of & Yes & 35 & 19.2 \\
\hline $\begin{array}{l}\text { school even if the child is not } \\
\text { sick }\end{array}$ & No & 145 & 80.8 \\
\hline Reasons for allowing miss a & Fear of seizure at school & 27 & 75.0 \\
\hline class for seizure $(n=35)$ & No particular reason & 3 & 8.3 \\
\hline & Other & 6 & 16.7 \\
\hline Another son/daughter, ever & Yes & 12 & 6.6 \\
\hline $\begin{array}{l}\text { missed a school day due siblings } \\
\text { seizures }\end{array}$ & No & 170 & 93.4 \\
\hline Guardians disclose child's & Yes & 159 & 86.9 \\
\hline epilepsy status to a teacher & No & 22 & 13.1 \\
\hline Guardians disclose child's & Yes & 105 & 57.4 \\
\hline epilepsy status to a peer & No & 78 & 42.6 \\
\hline
\end{tabular}


Table5. Factors associated with school absenteeism of school age children and adolescents with seizure disorder attending follow up at PNC in TASH between April and July, 2018

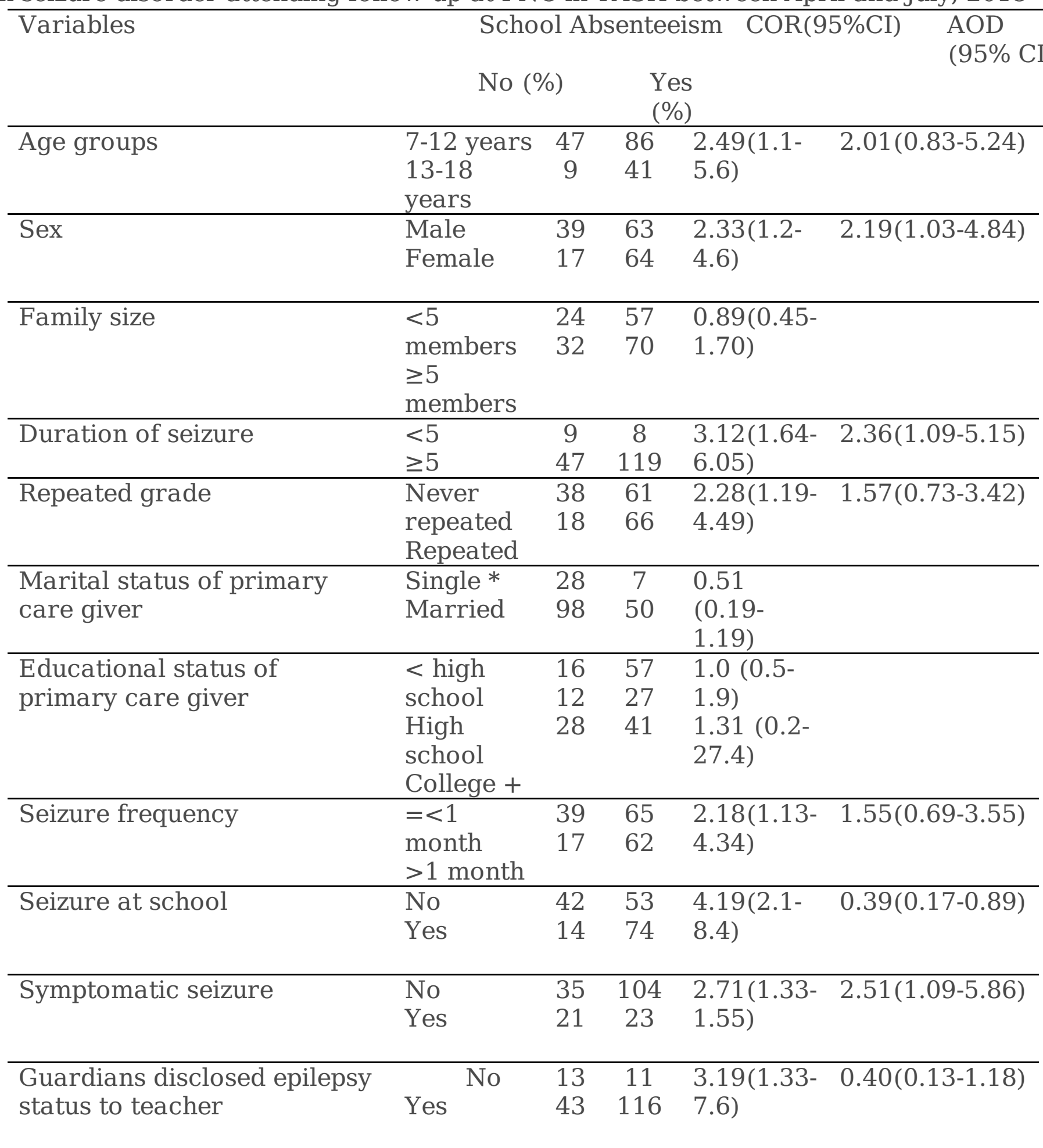

\section{Figures}




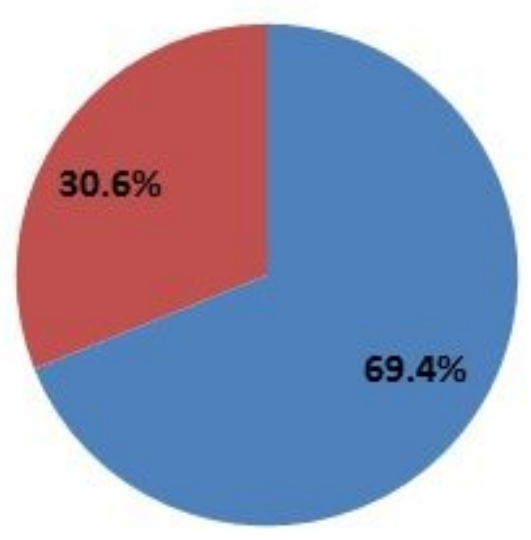

Yes No

\section{Figure 1}

Missed school; Percentage of students who miss school days among study participants of school age children and adolescents with seizure disorder attending follow up at PNC in TASH between April and July, 2018.

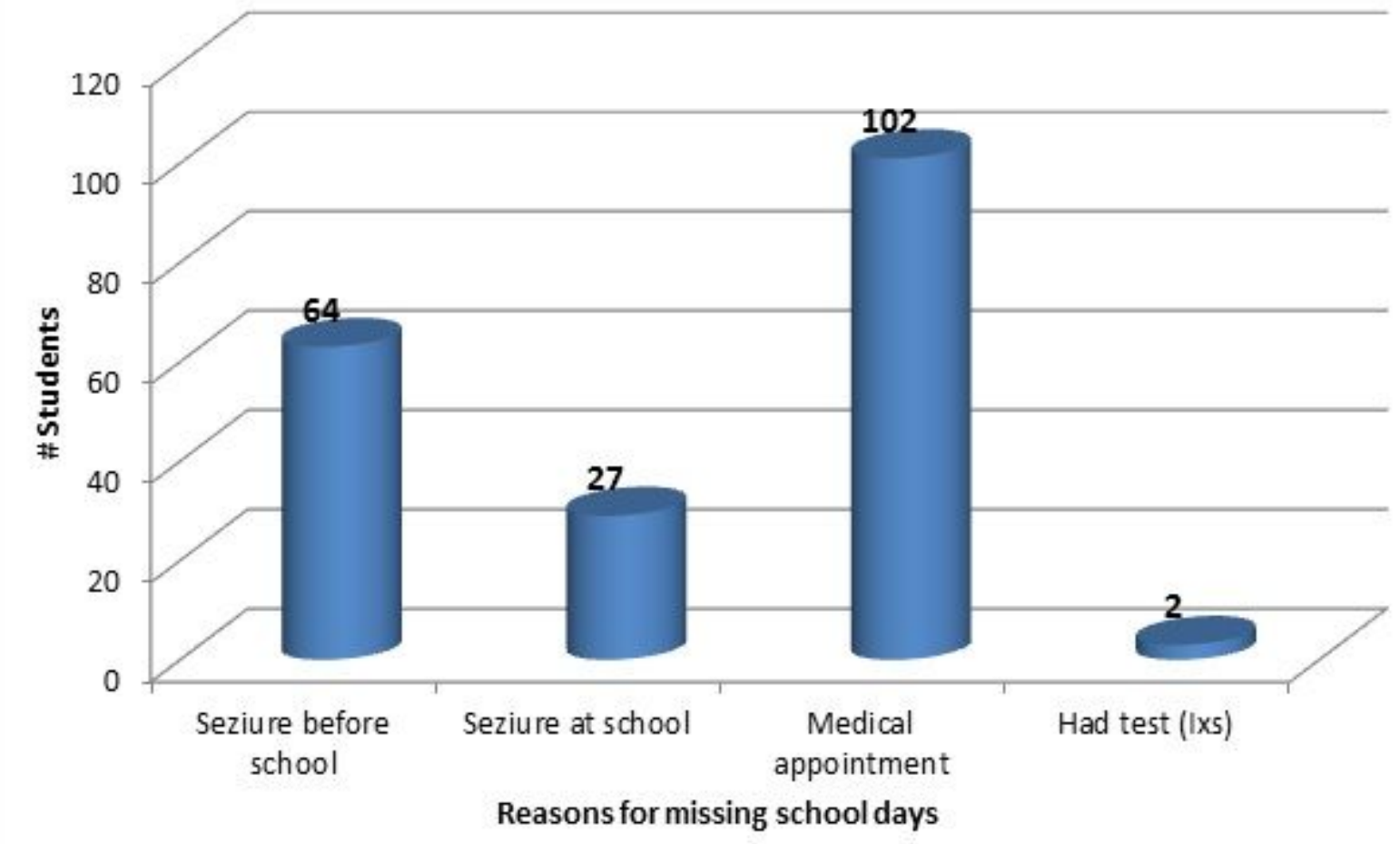

Figure 2 
Reason for missing school days among study participants of school age children and adolescents with seizure disorder attending follow up at PNC in TASH between April and July, 2018.

\section{Supplementary Files}

This is a list of supplementary files associated with this preprint. Click to download.

- STROBEchecklist.docx

- Annexes.pdf 